\title{
Research Article \\ IMPACT OF HIGH TEMPERATURE GRADIENTS ON THE PHYSIOLGICAL AND BIOMOLECULAR CHANGES IN THE TROPICAL TASAR SILKWORM Antheraea mylitta D
}

\author{
LOKESH G. ${ }^{*}$, MADHARIYA GARIMA ${ }^{2}$, SRIVASTAVA A.K. ${ }^{3}$, KAR P.K. ${ }^{4}$, SRIVASTAVA P.P. ${ }^{4}$, SINHA A.K. ${ }^{4}$ AND SAHAY ALOK ${ }^{4}$ \\ ${ }^{1}$ Central Sericultural Germplasm Resources Centre, Central Silk Board, Hosur, 635 109, India \\ 2Department of Biotechnology, Govt. V.Y.T. Post Graduate College, Durg, Chhattisgarh, 491001, India \\ 3S S Jain Subodh P G College, Jaipur, 302 004, Rajasthan, India \\ ${ }^{4}$ Central Tasar Research \& Training Institute, Central Silk Board, Ranchi, 835303, Jharkhand, India \\ ${ }^{*}$ Corresponding Author: Email - lokesh10csb@gmail.com
}

Received: May 18, 2018; Revised: May 24, 2018; Accepted: May 26, 2018; Published: May 30, 2018

\begin{abstract}
Tasar silkworm Antheraea mylitta D reared in tropical regions of the country and produce commercial tasar cocoons, which experiences extreme thermal condition during its life cycle. To perceive the thermo-tolerant characters of $A$. mylitta, in the present study, the tasar cocoons with live pupae were exposed/treated with high temperature in three different ranges $40-45^{\circ} \mathrm{C}, 46-50^{\circ} \mathrm{C}$ and $50-55^{\circ} \mathrm{C}$ in different time intervals. The treated pupae were collected, and the hemolymph and midgut tissues were examined for the changes in the protein and catalase activity through quantitative assay and electrophoresis. The experiment reveals a positive correlation of temperature and the protein concentration in the hemolymph and fatbody. Also, Catalase activity showed higher in thermal stress conditions compared to the control. The acute stress $\left(51-55^{\circ} \mathrm{C}\right)$ causes significant decrease in Catalase activity in the fat body of both males and female pupa. There are significant changes were observed in the electrophoretic protein profile with additional protein bands of $40 \mathrm{kDa}$ and $70 \mathrm{kDa}$ presumed as heat shock related proteins. Similarly, additional bands CAT3 \& CAT4 compared to control samples were observed in the catalase profile. The physiological changes observed in the tasar silkworm on high temperature treatment may be used as an indicator to identify the high temperature tolerant characters in the tropical tasar silkworms
\end{abstract}

Key words- Antheraea mylitta, temperature stress, Proteins, catalase, tropical tasar

Citation: Lokesh G., et al., (2018) Impact of High Temperature Gradients on the Physiolgical And Biomolecular Changes in the Tropical Tasar Silkworm Antheraea mylitta D. International Journal of Genetics, ISSN: 0975- 2862 \& E-ISSN: 0975-9158, Volume 10, Issue 5, pp.-420-424.

Copyright: Copyright@2018 Lokesh G., et al., This is an open-access article distributed under the terms of the Creative Commons Attribution License, which permits unrestricted use, distribution and reproduction in any medium, provided the original author and source are credited.

\section{Introduction}

The wild sericigenous insect species Antheraea mylitta Drury is widely exploited for forest based economic activity to produce tasar silk. This polyphagous tropical tasar silkworm is reared in central and eastern part of India, which experiences extreme thermal condition during its life cycle [1-3]. Among the forty-four ecoraces of $A$. mylitta reported, Daba is the most commercially exploited semi-domesticated ruling race reared in almost all tasar growing regions of India [4]. Temperature is a main abiotic factor for poikilothermic insects, it directly effects development and phenology of insects, their reproduction and mortality, their ability to exploit host plants, and their geographic distribution range. All biological processes including structure of proteins, biological membranes and rates of biochemical and physiological reactions affected due to high temperature stress $[5,6]$. The stress condition induces the changes in hemocytes of hemolymph and associated with physiological changes with release of higher rate of reactive oxygen species (ROS) in many insect species and particularly in silkworms [7-9] and hemocyte profile increases with an increased temperature and reduced hemocytes in the hemolymph when the silkworm exposed to lower temperatures [10-12]. The heat shock response is known to be evolutionarily and is a highly conserved biological response, exhibited by almost all living system $[13,14]$. It helps in physiological adaptability against not only heat but several metabolic stresses and toxicants $[15,16]$. Upon exposure of an organism to elevated temperatures, cells synthesize a small set of proteins, the heat shock proteins (Hsps). The Hsps have been regarded as molecular chaperones that provide protection to cellular components from the injurious effects of excessive heat and maintain cellular stability during heat stress [17-19].
In response to the higher level of ROS in the body, many enzymatic anti-oxidants will release to counteract in the defense mechanism. Study of these anti-oxidant enzymes during high temperature stress will be convenient to estimate the level of tolerance in the insects in response to the extreme temperatures [20,21]. Catalase (CAT) is the principal $\mathrm{H}_{2} \mathrm{O}_{2}$ scavenging enzyme which increases with increase in the insect's body temperature on exposure to higher external temperature [22] Since, there is less report on the heat shock or stress response in tasar silkworm Antheraea mylitta and with little/no understanding of threshold temperature (high) for the survivability of tasar silkworm, the present work has been undertaken to realize the above cited issues in the tasar silkworm as preliminary studies to possible development of temperature tolerant breeds of $A$. mylitta in future course of time to exploit them in hotter zones of the country to improve the tasar silk production
Materials and Methods
Collection of tasar silkworm cocoons and temperature treatments
Tropical tasar cocoons of Daba (semi-domesticate) race during late diapause period especially in the last week of June were collected and used for thermal treatment. The cocoons were subjected for three temperature treatments ranges i.e., $40-45^{\circ} \mathrm{C}, 46-50^{\circ} \mathrm{C}$ and $50-55^{\circ} \mathrm{C}$ and with different time intervals of treatments such as 1 hour, 2 hours, 4 hours, 6 hours and 8 hours in an environmental chamber with constant inside humidity of $65-75 \%$. In each treatments the sample size of 50 cocoons were maintained. After the treatment cocoons were preserved in room temperature $\left(28-32^{\circ} \mathrm{C}\right)$ till the moth emergence. 
Based upon the mortality, moth emergence, healthiness of the moth, survivability was recorded.

\section{Collection of tissue samples for the biochemical analysis}

Hemolymph and fat body from male and female pupa was collected separately within an hour after the completion of each treatments. Biological samples were preserved at- $20^{\circ} \mathrm{C}$ until further use.

\section{Quantitative estimation protein and catalase activity}

The total protein was estimated in hemolymph and fatbody of pupa following the method of [23] using Bovine Serum Albumin (BSA) as standard. The quantitative assay of Catalase activity was determined according to [24]. The method was based on the decomposition rate of $\mathrm{H}_{2} \mathrm{O}_{2}$ by the enzyme. The assay mixture

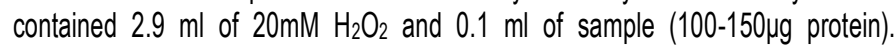
Absorbance was measured at $240 \mathrm{~nm}$ and CAT activity is expressed as nanoketal/mg protein (1 ketal $=1 \mathrm{~mol} \mathrm{sec}-1)$.

\section{Electrophoretic analysis of proteins to study the HSPs.}

The qualitative analysis of proteins was carried out through electrophoresis to recognize the proteins related to heat shock response in the hemoloymph and fatbody. Protein polymorphism in the hemolymph and fatbody of pupa of different treatments was analyzed using SDS-PAGE (sodium dodecyl sulfate polyacrylamide gel electrophoresis) with slight modification $[25,26]$. The hemolymph protein samples were subjected to electrophoresis in $4.5 \%$ stacking gel initially and protein separation was done in $12 \%$ resolving gel. The resolved proteins were visualized by Coomassie Brilliant Blue (CBB-250) and documented.

\section{Native Gel electrophoresis analysis of Catalase}

Catalase (CAT) was studied in the pupal hemolymph sample by Native gel electrophoresis. The gel matrix was prepared using chemical mixers mentioned below along with $5 \%$ soluble starch. Electrophoresis was conducted using common gel matrix formulation except for the Catalase analysis. The staining solution was used separate and specific for each isozyme studied [27].

\section{Results \\ Study of biochemical changes in response to high temperature Quantitative assay of total proteins}

The quantitative assay of proteins in the pupa showed significant increase in protein concentration in the hemolymph and fat body in the pupae exposed to high temperature. Higher protein concentrations were recorded in the pupa treated sets $(230 \mathrm{mg} / \mathrm{ml}$ in hemolymph and $205 \mathrm{mg} / \mathrm{ml}$ of fat body) of temperature treatment range $51-55^{\circ} \mathrm{C}$. Protein concentration also showed a positive correlation with the temperature in the present observations made in both the tissues [Fig-1]. Amongst, female recorded higher protein concentration compared to male in all the batches.

\section{Estimation of Catalase activity}

Catalase activity levels in the three different temperature ranges showed significant difference in selected tasar silkworm fat body tissue. The CAT activity in thermal stress conditions [Fig-2-7] showed higher compared to the control. Further acute stress $\left(51-55^{\circ} \mathrm{C}\right)$ causes significant decrease in the fat body Catalase activity in both males and female pupa. The temperature range $40-45^{\circ} \mathrm{C}$ and 46 $50^{\circ} \mathrm{C}$ showed increased Catalase activity.

\section{Qualitative analysis of proteins through SDS-PAGE in response to high temperature stress}

The SDS-PAGE analysis of in the pupa total proteins in hemolymph and fat body treated with different temperatures and different time intervals were studied for the assessment of high temperature stress. Polymorphic variations were noticed about the number of protein bands in the hemolymph samples. More number of protein bands was recorded corresponding to the quantitative total proteins in male and female pupae, also in all treated individuals. Appearance of $35 \mathrm{kDa}$ Protein band was significant in the female hemolymph samples of all the populations this might be the sex specific protein bands (W chromosomes). The protein bands at higher molecular weight were constantly present in both fat body and hemolymph samples. Significant appearance of protein bands of $40 \mathrm{kDa}$ and $70 \mathrm{kDa}$ in the high temperature treated sample the same protein bands were appeared in both fat body and hemolymph of pupa as well as appeared in the fat body sample of F1 larva. Over all, there was an apparent polymorphism in electrophoretic protein bands with the constitutive appearance of some protein bands in all the samples studied [Plate-1-6].

\section{Electrophoresis and localization of Catalase activity}

The electrophoretic profile of Catalase (CAT) of pupal fat body and hemolymph samples showed a significant difference in the level of expression. The temperature treatment at $40-45^{\circ} \mathrm{C}$ and $46-50^{\circ} \mathrm{C}$ showed more number of bands compared to the control samples. Three prominent catalases such as CAT1, CAT2, CAT3 were observed in the treated sets whereas control set recorded only CAT3. Higher expression of Catalase in respect of more bands appearance in the electrophoresis confirms the higher activity recorded in the quantitative estimation of the enzyme activity in the high temperature exposed samples[Plate-7].

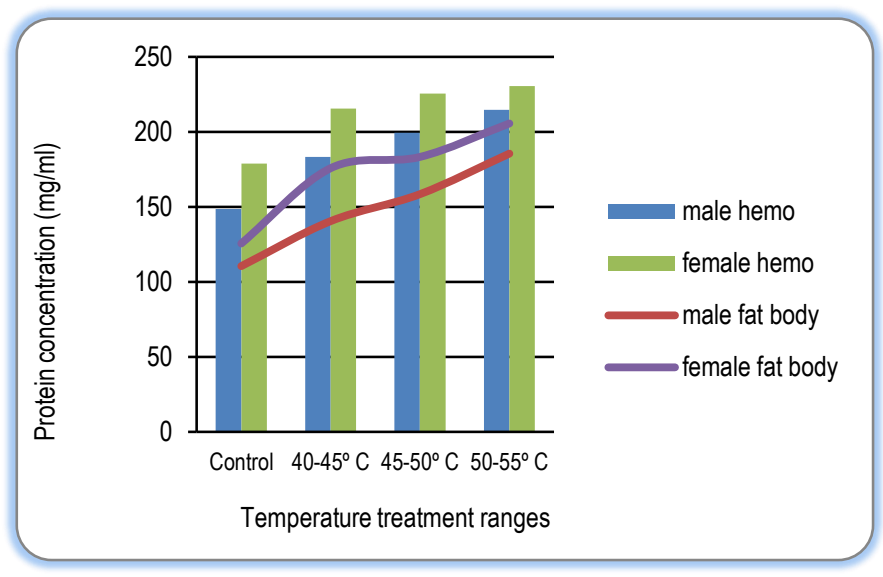

Fig-1 Total protein concentration in hemolymph and fat body of tasar silkworm A.mylitta pupa in different temperature gradients and intervals.

\section{Discussion}

High temperature affects nearly all biological processes including structure of proteins, biological membranes, and rates of biochemical and physiological reactions. The present study was intended to investigate the level of physiological effects in pupal stage of tasar silkworm A. mylitta due to high temperature stress and to pursue the suitable temperature range/ threshold temperature for the induction of thermo-tolerant molecules in tasar silkworm. The protein levels in the haemolymph increased significantly in response to high temperature due to high metabolic rate and synthesis of new proteins by the tissues and release into haemolymph [28]. This also confirms that proteins are not a source of energy in the stress condition but are involved in the modulation of silkworm physiological activity to protect from temperature stress [29]. Some new proteins synthesized are also involve in the metabolic synthesis of biomolecules such as glycerol, sorbitol and other polyols acts as thermoprotectants [30,31] are synthesize in the tissues and release into the hemolymph to protect organisms during adverse conditions like temperature stresses [32]. Some important sugar compounds are synthesized during non-feeding stage of the silkworm as a source to meet the emergent energy needs as well as their utilization in the production of some new proteins/ biomolecules to cope with the temperature stress. Catalase (CAT) in insects has been solely responsible for the scavengery of $\mathrm{H}_{2} \mathrm{O}_{2}$, because insects are deficient in a selenium-dependent glutathione peroxidase that is another scavenger present in other organisms [33,34]. There are however, few reports describing biochemical properties of insect CAT. In the present investigation, the activity of CAT was studied in response to high temperature stress in the fat body of $A$. mylitta pupa and it is found a great difference $(P<0.001)$ in amount of CAT activity observed in three different temperature ranges as well as observed relatively high activity in the fat body at $46-50^{\circ} \mathrm{C}$ and $40-45^{\circ} \mathrm{C}$ respectively. 

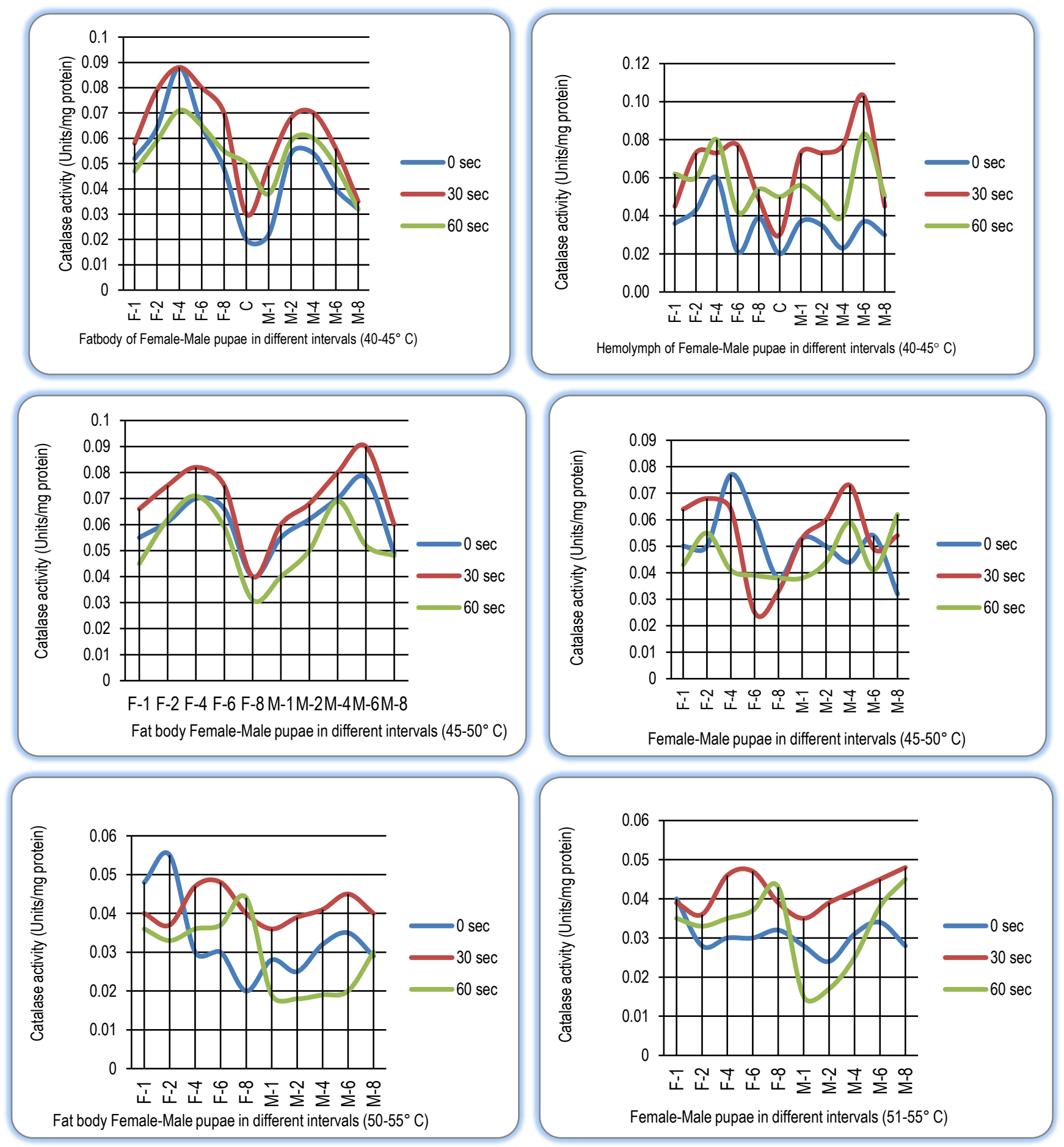

Fig-2-7 Catalase activity in fat body and hemolymph of tasar silkworm A. mylitta pupa in different temperature gradients and time intervals

This could happen due to more metabolism level in the fat body tissue during this temperature range in the tasar silkworm pupa. These results were interesting, because the fat body plays a physiological role like that of the liver in mammals [35]. Many authors described the physiological responses Bm CAT (Bombyx mori catalase) also plays a significant role most probably in curing the oxidative stress by facilitating the degradation of $\mathrm{H}_{2} \mathrm{O}_{2}$. In this context, it was exhibited that irradiation of gamma rays to $B$. Mori larvae causes a notable increase in CAT activity in the midgut and fat body. The increase in enzyme activities explain that ROS are overproduced due to heat stress which have resulted into upregulation of enzyme activities [36]. In the present study, temperature is also an abiotic physical factor have direct implications on the silkworm's physiological processes on stress. The presence and absence of few protein bands at specific site (Molecular weight) indicates the synthesis of a protein to meet the physiological need. The higher protein bands $>80 \mathrm{Kda}$ are found common in all the hemolymph and fat body samples are known to be storage proteins in lepidopteron. This could be also of species specific proteins, presumed to found in all the ecoraces of the $A$. mylitta. It was showed that the protein bands of 36 and $64 \mathrm{Kda}$ are constitutively appeared in all the tissues studies in A. myltta [37]. This is attributed to the higher protein concentration recorded in the quantitative estimation in the high temperature treated silkworms. The presence of serum protein (BmLSP) appeared as thick protein bands near the region $29 \mathrm{kD}$ [38] in the protein extracted from the B.mori hemolymph. In the present study, the appearance of new proteins in the high temperature exposed samples presumed to be the heat shock related proteins. The survivability of the silkworm at extremes of heat relates to counter effects of heat shock proteins, serving as molecular chaperones assisting in refolding of denatured proteins. Also, the haemolymph being an open circulatory system, most of the tissues including the fat bodies bathed in haemolymph within the body. 
Impact of High Temperature Gradients on the Physiolgical And Biomolecular Changes in the Tropical Tasar Silkworm Antheraea mylitta D

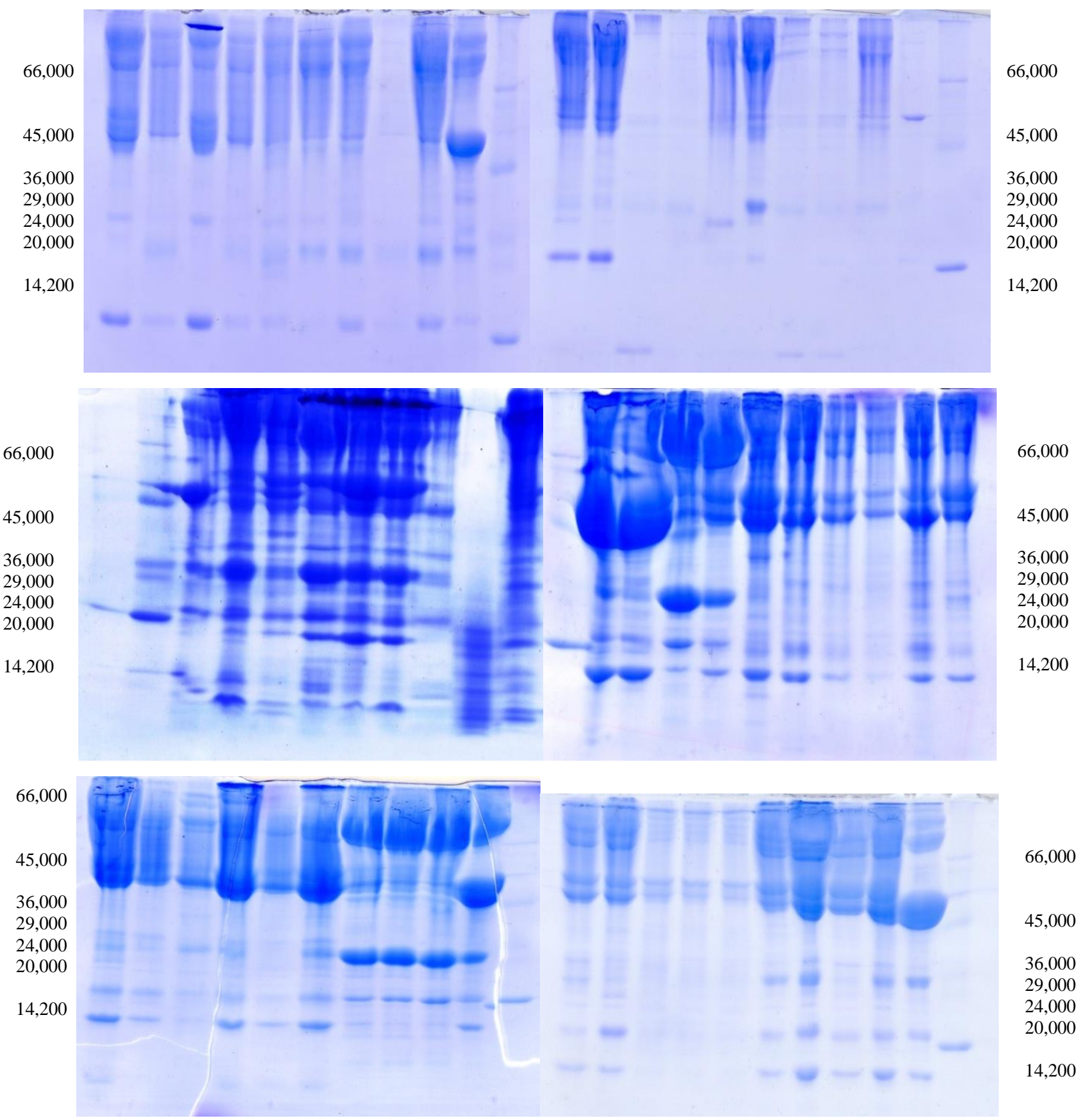

Plate-1-6 SDS-PAGE protein profile of pupal hemolymph and fatbody of $A$. mylitta treated at three temperature gradients $1.40-45^{\circ} \mathrm{C}, 2.46-50^{\circ} \mathrm{C} \& 3.51-55^{\circ} \mathrm{C}$ for different time duration.

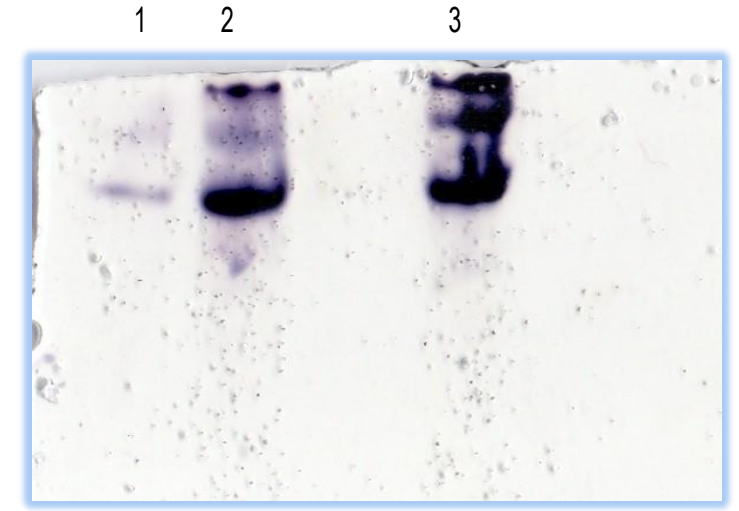

a

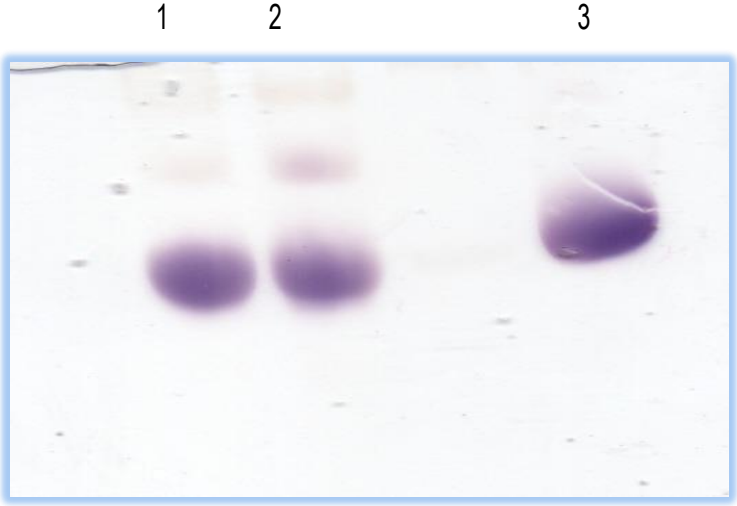

b

Plate-7 Native PAGE catalase profile in the a. fatbody and b. hemolymph of $A$. mylitta pupa treated at three temperature gradients 1. Control, $2.40-45^{\circ} \mathrm{C}, 3.46-50^{\circ} \mathrm{C}$. 
Consequently, several proteins synthesized in the fat body find their way into the haemolymph. In this respect, the presence of Hsp72 in the hemolymph of $B$. mori can be considered as a desirable feature in conferring thermotolerance to the larvae. Expression of heat shock proteins in different tissues also varies depending on the stage of development or even the temperature at which the exposure was given. The total concentration of Hsp and their redistribution to specific intracellular sites are considered as most important factors in the acquisition of thermotolerance [39]. The synthesis of proteins in fat body induced by heat shock at different temperatures was analyzed. Seven polypeptides with apparent molecular weights of $90,70,65,40,37,22$ and $18 \mathrm{kDa}$ were observed in the fat body and hemolymph of domesticated silkworm [40]. Heat shock led to the synthesis of 70 and $40 \mathrm{kDa}$ proteins constitutively in the A. mylitta seems more persuasion is required to confirm this aspect in this species. The Catalase (CAT) of pupal hemolymph and fat body expressed four prominent catalases such as CAT1, CAT2, CAT3 and CAT4, three bands found common in all the samples. Each of different catalases has specific functions present in different eukaryotes as well as prokaryotes. The expression of these catalases depends on the genetic constituent, stage, sex some extent implications of environment of the insects [41]. Also shown that mutants deficient in the key antioxidant enzymes catalase, superoxide dismutase and cytochrome-c peroxidase are sensitized to a $50^{\circ} \mathrm{C}$ heat exposure, whilst over expression of catalase and superoxide dismutase provides protection from lethal heat shock [42]. The catalase electrophoretic study in tasar silkworms needs to be further pursued for better clarity with more samples and replications. Moreover, this is a preliminary confirmation that heat stress on $A$. mylitta leads to express more catalases. Since the tropical tasar silkworm represents significant variability in its wide spread population.

Application of research: Identifying the high temperature tolerant traits in these populations is highly desirable. The protein and enzyme markers with reliable techniques will help in identification of thermo-tolerant breeds /line which can be used in the high temperature zones to raise higher tasar silk productivity.

Research Category: Silkworm improvement, thermo-tolerant lines

Abbreviations: CAT-Catalase, kDa-Kilo Dalton, HSPs-Heat Shock Proteins

Acknowledgement / Funding: Author thankful to Central Tasar Research \& Training Institute, Central Silk Board, Ranchi, 835303, Jharkhand, India

\section{*Principle Investigator: Dr G. Lokesh}

Institute: Central Sericultural Germplasm Resources Centre, Central Silk Board, Hosur, 635109

Research project name or number: Nil

\section{Author Contributions: All author equally contributed}

Author statement: All authors read, reviewed, agree and approved the final manuscript

\section{Conflict of Interest: None declared}

Ethical approval: This article does not contain any studies with human participants or animals performed by any of the authors.

\section{References}

[1] Hansda G., Manohar Reddy R., Sinha M.K., Ojha N.G. and Vijaya Prakash N.B. (2008) Intl J. Indus. Entomology, 17(2), 169-172.

[2] Sinha B.R.R.P. and Srivastava A.K. (2004) Perspectives in Cytology and Genetics, 11, 243-249.

[3] Suryanarayana N., Kumar R. and Gargi (2005) Central Tasar Research and Training Institute, CSB, India.

[4] Suryanarayana N., Srivastava A.K. (2005) Central Tasar Research and Training Institute, CSB, India.
[5] Hazel J.R. (1995) Annu. Rev. Physiol., 57, 19-42

[6] Willmer C. W., Stone G. and Johnston I. (2004) Blackwell Science,

[7] Pandey J.P., Mishra P.K., D Kumar, Singh B.M.K. and Prasad B. C. (2010) Research Journal of Immunology, 3(2), 169-177.

[8] Lokesh G., Kar P.K., Srivastava A.K, Saloni Swaroopa, Sinha M.K. (2012) Int. J. Indst. Entomol., 24(1), 69-74.

[9] Jena K.B., Kar P. K., Zeba Kausar and Babu C. S. (2013) Journal of Thermal biology, 38,199-204.

[10] Blacklock B.J. and Ryan R.O. (1994) Mol.Bio., 24, 855-873.

[11] Tiwary R.K. and Shukla R.S. (2000) Proc. Nat. Aca. Sci. India, 70, 243-254.

[12] Chaubey A.K. (2002) Ph.D. thesis VBS Purvanchal University, Jaunpur, India

[13] Schlesinger M. J., Ashburner M. and Tissiers A. (1982) Cold Spring Harbor, New York: Cold Spring Harbor Laboratory.

[14] Lindquist S. and Craig E.A. (1988) Annu. Rev. Genet., 22, 661-677.

[15] Petersen N. S. (1990) Adv. Genet., 28, 275-296.

[16] Casey T. M. (1977) Comp. Biochem. Physiol., 57A, 53-58.

[17] Deshaies R.J., Koch B.D., Werner-Washburne M., Craig E.A., Schekman R. (1998) Nature, 332,800-805.

[18] Welch W. J. (1991) Curr. Opin. Cell. Biol., 3, 1033-1038.

[19] Fittinghoff C.M. and Riddiford L.M. (1990) J. Comp. Physiol., B, 160, 349-356.

[20] Kaur P., Kaur G., Bansal M.P. (2006) Reprod. Toxicol., 200, 479-484.

[21] Aitken R.J., Roman S.D. (2008) Oxid. Med. Cell Longev., 1(1), 15-24.

[22] An M.I. and Choi C.Y. (2010) Comp.Biochem. Physiol., 155, 34-42.

[23] Lowry O.H., Rosebrough N. J., Farr A.L. and Randall R. J. (1951) J. Biol. Chem., 193, 267-275.

[24] Aebi H. (1984) Method Enzymol., 105, 121-126.

[25] Zingales B. (1984) Ed. By Morel C. M. 2nd Edn. Fundacao Oswaldo Cruz, Rio' de Janeiro, Brazil, 357-363

[26] Lokesh G., Bishnu Prasad, Srivastava A.K., Srivastava P.P., Kar P.K. and Sinha M.K. (2014) Intl. Res. J. Biol. Sci., 3(11), 42-46.

[27] Staykova T. (2008) J Insect Sci., 8, 1- 8.

[28] Joy Omana and Karumathil P Gopinathan (1995) Journal of Biosciences 20(4): 499-513.

[29] Singh Anita, Ratnesh Kr Sharma and Bechan Sharma (2010 Insect Physiology, 2, 11-16.

[30] Wolfe R Gregory, Donald L. Hendrix, Michael E. Salvucci (1998) Journal of Insect Physiology, 44, 597-603.

[31] Shamitha G. and Purushotham Rao A. (2008) Asian J. Exp. Sci., 22(3), 255-260.

[32] Forcella M., Berra E., Giacchini R., Parenti P. (2007) Archv Insect Biochem Physiol., 65, 181-194.

[33] Ahmad S. and Pardini R.S. (1990). Free Radic. Biol. Med., 8, 401-413.

[34] Sohal R.S., Arnold L. \& Orr W. C. (1990) Mech. Ageing. Dev., 56, 223235.

[35] Keeley L. L. (1985) In: Kerkut G. A., Gilbert L. I. (Eds.)

[36] Kaur P., Ghai N. and Sangha M.K. (2009) African J. of Biotech., 8(4), 619-625.

[37] Kumar D., Pandey J.P., Jain J., Mishra P.K., Prasad B.C. (2011) Int. J. Zool. Res., 7(2), 147-155.

[38] Fujiwara, Y. and Yamashita O. (1990) Insect. Biochem., 20, 751-759.

[39] Kampinga H.H. (1993) Journal of Cell Science, 104, 11-17.

[40] Howrelia J. Hongray, Patnaik B.B., Selvanayagam M. and Rajakumar S. (2011) J. Envi.Bio., 32(1), 99-103.

[41] Davidson J. F., Whyte B., Bissinger P.H. \& Schiestl R.H. (1996) Proc Natl Acad Sci USA, 93, 5116-5121.

[42] Maria A.N.J., Ricardo M.C., Maria H.S.G., Jesus A., Suresh lyer, Allan C., Hector F.T. and Gustov H.G. (1999) Microbiology, 145,3229-3234. 